\title{
Patrimonio cultural y turismo
}

\section{Antonio La Cotera}

\section{Patrimonio cultural de la nación}

\section{Generalidades}

El patrimonio cultural del Perú es considerado uno de los más variados de América por sus numerosos bienes históricos, artísticos, acervo folklórico, riqueza arquitectónica, entre otros. Cada región o población tiene características que hacen del nuestro un país pluricultural.

En la actualidad el patrimonio cultural está desatendido por las autoridades competentes. En comparación con otros países, el Estado peruano asigna un presupuesto irrisorio para investigaciones y avances tecnológicos. Sin embargo, el descuido de nuestro patrimonio no se debe sólo al factor económico, sino, en gran medida, a la educación que se imparte. Muchas personas desconocen la relevancia histórica del patrimonio cultural. El Gobierno debe poner más atención a este problema y encontrar mejores vías de solución.
Este desconocimiento se debe a la falta de información. Muchos pobladores que viven en asentamientos humanos ubicados en lugares arqueológicos ignoran la importancia de éstos. Garagay es un buen ejemplo de ello. En este lugar priman las necesidades de vivienda antes que el afán de conservar el patrimonio de nuestros antepasados.

A ello se suma el daño que ocasionan los buscadores de tesoros, traficantes de antigüedades, que operan tanto dentro como fuera del Perú. La Ley de Amparo del Patrimonio Cultural (24047) deja muchos vacíos que permiten, de manera indirecta, el contrabando de restos arqueológicos.

Instituciones nacionales y particulares que podrían velar por el patrimonio y luchar contra esa lacra delincuencial pierden interés al no recibir respaldo del Gobierno. Esta es una de las principales razones del deterioro de dichas zonas, por lo que tenemos que invocar la ayuda de entidades internacionales para desarrollar una 
política de conservación. El Estado debe propiciar la formación de patronatos encargados de supervisar y controlar la protección de los monumentos.

El crecimiento urbano y la ejecución de obras públicas también afectan a los monumentos arqueológicos. Un ejemplo de ello es lo ocurrido en Pachacámac, donde, para hacer la carretera Panamericana Sur, se devastó la parte central hasta el puente Lurín.

Los medios informativos son los que más podrian ayudar a educar a la población, incluyendo en sus proyectos líneas de acción a favor de la conservación de nuestro patrimonio. Existen programas culturales que no cumplen su objetivo, al no despertar el interés sobre estos temas. De no tomar en serio este problema y de no lograr soluciones inmediatas, puesto que no se trata de algo secundario, corremos el riesgo de perder nuestra identidad como nación.

\section{Marco conceptual}

Los diferentes conceptos de patrimonio cultural existentes tienden a transmitir la preocupación de cada uno de sus autores, según su propio interés, medio o profesión. Entre ellos seleccionamos la definición que da el doctor Manuel Osorio en su Diccionario de ciencias jurídicas, políticas y sociales, por ser la que más se aproxima a nuestra realidad: "Conjunto de obras de arte, de monumentos históricos o literarios que pertenecen a una nación y que son objeto de protección legal por parte del Estado, no sólo para los efectos de conservación, sino también para su permanencia dentro del país". Esa protección no sólo alcanza a los bienes que pertenecen a la Nación, sino también a la propiedad particular, para impedir su salida ilegal a otros países.

Los bienes que integran el patrimonio cultural peruano se dividen en dos grandes rubros: inmuebles y muebles. Entre los bienes inmuebles se considera a los ambientes $y$ monumentos. Como un ejemplo de ambiente se puede citar a las Pampas de la Quinua, en Ayacucho. $Y$ entre los monumentos tenemos a Machu Picchu, la Catedral de Lima, el Hospital Dos de Mayo, el Palacio de Torre Tagle, y otros. Los bienes muebles se clasifican en prehispánicos, coloniales y republicanos, y comprenden una amplia tipología, como por ejemplo un ceramio mochica, la indumentaria de oro del Señor de Sipán, una pintura, un retablo tallado, un incensario de plata, etc. A esta clasificación se suma otro tipo de bienes que conforman el denominado patrimonio inmaterial. Ejemplos de ello son la música, el folclor, manifestaciones espontáneas y permanentes de las costumbres de un pueblo; asi como nuestro patrimonio bibliográfico y documental, expresión del trabajo intelectual, científico, literario o tecnológico.

\section{Marco normativo}

La Constitución Política de 1993 tiene límites en relación al ámbito cultural. En ella ubicamos sólo un artículo sobre los bienes que pertenecen al patrimonio cultural, su situación jurídica y la participación privada en la conservación, restauración, exhibición y difusión del mismo. Este único punto es taxativo, porque ignora ciertos aspectos de la cultura, como el promoverla en beneficio de la formación de una sólida identidad nacional.

En la Constitución de 1979 se planteó el tema cultural con mayor criterio y amplitud que en la actual Carta Magna. Esto se aprecia en los cuatro artículos siguientes: El artículo 34 se refería a la preservación y al estudio de las manifestaciones culturales nativas: el folclore nacional, el arte popular y la artesanía. El artículo 35 establecía la obligación del Estado de incentivar el estudio de las lenguas aborígenes.

El artículo 36 trataba sobre los bienes que constituyen el Patrimonio Cultural de la Nación. Finalmente, el artículo 37 hacía referencia a la función de los medios de comunicación social del Estado en la educación y la difusión de 
la cultura. De ellos, el artículo 36 es el único punto vigente en la Constitución Política de 1993 (artículo 21).

Convenios internacionales como los de la Unesco (1972) y San Salvador (1976) precisan qué evidencias del pasado histórico del ser humano son consideradas como "bien o patrimonio cultural".

El Código Civil de 1984, en sus artículos 885 y 886 , contribuye al reconocimiento e identificación de los bienes muebles e inmuebles.

El Código Penal de 1991 (artículos 226 al 231) establece penas ${ }^{\circ}$ contra todo acto de sustracción y ataque al patrimonio. A nuestro criterio, tales sanciones son muy blandas en relación a la magnitud de los delitos, pues está en juego el pasado histórico de una nación.La Ley 24047 (Ley General de Amparo al Patrimonio Cultural de la Nación), promulgada en 1985, es insuficiente para proteger nuestro patrimonio, por no estar correctamente estructurada y por confundir aspectos administrativos y terminológicos.

La Ley Orgánica de Municipalidades, publicada en el Diario Oficial El Peruano el 9 de junio de 1984, precisa en su artículo 67 las funciones específicas de los concejos con respecto a la educación, cultura, conservación de monumentos, turismo, recreación y deportes.

Para iniciar el análisis de las normas jurídicas que regulan el tema que nos ocupa, debemos tomar en cuenta un primer aspecto. Existe una diferencia abismal entre los conceptos de Estado y nación, que en la legislación estudiada están considerados como sinónimos. Nación es la capacidad que tiene el pueblo para hacer cumplir sus derechos y regir sus deberes. Estado es la institución que realiza esta función en representación de la nación. Es decir, el Estado es una consecuencia de la decisión de la nación, que muchas veces desconoce la capacidad de que goza.
Constitución Política del Estado de 1993. Título I: De la Persona y la Sociedad. Capítulo II: De los Derechos Sociales y Económicos

La Constitución regula, en su artículo 21, lo que puede ser considerado patrimonio cultural de la nación, independientemente de su condición, sea ésta pública o privada. Expresa que está protegido por el Estado y que la ley garantiza la protección a la propiedad de los bienes culturales. Fomenta, conforme a ley, la participación privada en la conservación, restauración, exhibición y difusión de estos bienes y regula su restitución al país, en el caso que fueran sacados ilegalmente.

Tardíamente, el Estado reconoce que debe defender el muy descuidado y mermado patrimonio cultural de la nación. $Y$ no exageramos al afirmar que nuestros bienes han sido saqueados a través de los años. Un ejemplo de ello es lo sucedido con el Señor de Sipán, catalogado como uno de los grandes hallazgos de la humanidad y que sin embargo, al ser descubierto, evidenciaba un inescrupuloso saqueo.

En cuanto a la función del Estado respecto a la conservación y difusión del patrimonio, es muy poco lo que se observa en la realidad, dado el exiguo presupuesto asignado a estas actividades. Sin embargo, el párrafo final del artículo 21 de la Constitución, que pone énfasis en la posibilidad de inversión privada para recuperar y mostrar el patrimonio cultural del país, está expresado con más detenimiento en la Ley 24047. Por ello, se debería estudiar más atentamente las modificaciones realizadas en esta norma, para no caer en los mismos errores.

Otra de las funciones del Estado es la de gestionar la restitución de los bienes culturales que se hallan en forma ilegal en territorio ajeno al de su origen. Al respecto, el Memorándum de Entendimiento suscrito entre el Perú y Estados Unidos el 9 de junio de 1997, busca restringir el tráfico ilícito de bienes culturales muebles. El referido instrumento legal ha logrado el retorno al país de piezas arqueológicas pertenecientes al 
Señor de Sipán, saqueadas en 1987 y que fueron comercializadas de manera clandestina fuera y dentro del Perú. Este compromiso es de obligatorio cumplimiento para estadounidenses y peruanos, según lo establecido en la Convención de la Unesco de 1970.

Asimismo, se prescribe que el Perú deberá organizar programas de capacitación para arqueólogos, etnólogos y, sobre todo, para el personal que labora en los museos. Similar criterio debe aplicarse con las instituciones responsables de la protección y salvaguarda del patrimonio cultural.

Debido a la ineficacia de la norma legal respecto al patrimonio cultural, se hace cada vez más difícil que el Perú proceda de manera objetiva y coherente cuando se presenta ante las cortes internacionales. Actualmente existe la convicción de utilizar a nuestro patrimonio cultural como simple atractivo turístico. Por ello coincidimos con Mariana Mold de Pease cuando, en su artículo "Para entendernos mejor" (El Comercio, 17/8/98), nos dice: "La red de trabajo de los traficantes de bienes culturales es infinitamente más creativa, articulada e internacional que la legislación peruana". La falta de una ley que proteja, defienda y conserve nuestro patrimonio cultural, hace posible que esa mafia irreverente $e$ inescrupulosa siga cometiendo hechos claramente punibles.

El artículo 66 de la Constitución, Título III: Del Régimen Económico. Capítulo II: Del Ambiente y los Recursos Naturales, considera patrimonio de la nación a los recursos naturales, sean estos renovables o no. Creemos que este artículo es complementario del artículo 21 de la misma Carta Magna. Y la finalidad de llamar la atención del lector es para remarcar la diferencia establecida al inicio del tema, entre bienes muebles e inmuebles con respecto a su ubicación y el uso dado a éstos a través del tiempo.
Código Civil de 1984. Libro V:

Derechos Reales.

Sección Segunda: Bienes.

Título I: Clases de Bienes.

Título II: Propiedad.

Capítulo Segundo: Adquisición de la propiedad. Subcapítulo I:Apropiación. Capítulo Tercero: Propiedad predial. Subcapítulo I:

Disposiciones Generales

Los artículos 885 y 886 del Código Civil vigente establecen la clasificación doctrinaria de los bienes, según las características comunes que ostentan. En primera instancia, por su naturaleza, los bienes pueden ser muebles e inmuebles. En segundo lugar, según el titular del derecho, bienes de particulares o del Estado. Esta última distinción subsiste en otros dispositivos, como la Ley 24047.

Para establecer el orden entre nuestro desarrollo y este título, hay que decir que los bienes culturales son aquellos especificamente declarados como tales. Existe una presunción provisional para darles ese título, y puede funcionar respecto de cualquier bien. La Convención de San Salvador, del 16 de junio de 1996, favorece la identificación, registro, protección y vigilancia de los bienes que integran el patrimonio cultural de las naciones americanas. Establece el vínculo entre los bienes incluidos en esta convención, y señala las obligaciones de los Estados adherentes, como es el caso del Perú, respecto a sus bienes culturales y a los de otras naciones.

En consecuencia, los bienes culturales pertenecen a la nación, pueden ser de propiedad privada o pública, pero su protección corresponde al Estado. La ley garantiza esa propiedad y establece requisitos y restricciones como, por ejemplo, el de inscribir los bienes culturales en los registros del Instituto Nacional de Cultura, exigencia que no se cumple a cabalidad.

Es necesario destacar que los casos sobre apropiación de un bien, regulados en los 
artículos $934^{\circ}, 935^{\circ}$ y $936^{\circ}$, se refieren específicamente al descubrimiento de tesoros en terrenos ajenos. Cuando dichos predios están cercados, sembrados o edificados, el hallazgo pertenece al dueño del mismo. Si no cumplen con lo anterior, se dividirá entre el propietario y el descubridor. El artículo $936^{\circ}$ establece que sólo procederá esta apropiación cuando no se oponga a las normas que regulan el patrimonio cultural de la nación. Y por último, en el segundo párrafo del artículo $954^{\circ}$ del Código Civil vigente, se prescribe: "La propiedad del subsuelo no comprende los recursos naturales, los yacimientos y restos arqueológicos, ni otros bienes regidos por leyes especiales".

\section{Código Penal de 1991.}

Título VIII: Delitos contra el Patrimonio Cultural. Capítulo Unico: Delitos contra los Bienes Culturales.

La función principal del Código Penal vigente es la sanción. El Estado emplea esta norma para establecer las penas contra los responsables de hechos punibles. Este capítulo contempla condenas para quienes, de manera ilícita, depreden o exploten zonas reconocidas como yacimientos arqueológicos prehispánicos. La medida, sin embargo, no ha amedrentado a los llamados "huaqueros", pues a la fecha no conocemos ningún caso en que se haya hecho efectivo su cumplimiento. Asimismo, consideramos insuficiente la sanción que establece para los casos de exportación y no retorno de las piezas autorizadas para salir del país.

Es lamentable comprobar la corrupción que impera entre las autoridades responsables. Una muestra de ello es la constante salida de piezas que pertenecen a nuestro patrimonio cultural. En ese sentido, la Organización de los Estados Americanos ha suscrito la Convención Interamericana contra la Corrupción, en Caracas, Venezuela, el 29 de marzo de 1996, a fin de no socavar la legitimidad de las instituciones públicas y, más aun, no dañar a las sociedades de los países signatarios. También es destacable el Memorándum de Entendimiento suscrito entre los gobiernos de Estados Unidos y el Perú, que impone restricciones a la importación de piezas prehispánicas y cierto material etnológico del período colonial del Perú.

Ley General de Amparo al Patrimonio Cultural de la Nación:

Ley 24047 del 3 de enero de 1985

Al estudiar esta ley encontramos puntos importantes y discutibles que a través del tiempo han adquirido un enfoque político, lo que demuestra el desinterés de las autoridades encargadas de la protección del patrimonio cultural.

La Ley General de Amparo al Patrimonio Cultural sostiene, entre otros lineamientos, que el Instituto Nacional de Cultura es el principal encargado de la protección y conservación del patrimonio. Asimismo, declara la responsabilidad de diversas instituciones culturales. Al respecto, debemos precisar que no se establece la participación de los medios de comunicación, los cuales, debido a su alcance $e$ influencia, deberían asumir la responsabilidad de informar $y$ difundir nuestro patrimonio cultural.

En sus artículos 9 y 10, la Ley 24047 crea el Consejo del Patrimonio Cultural de la Nación. El artículo 9 especifica quiénes serían sus integrantes y se mencionan doce representantes de las más importantes instituciones culturales del país. El artículo 10 estipula las atribuciones que tendría este consejo, entre ellas, aprobar proyectos relacionados con inventarios, conservación, restauración y cooperación internacional. Todo ello quedó en letra muerta, pues, durante la vigencia de dicha ley, el consejo nunca se creó.

El Instituto Nacional de Cultura tiene entre sus principales funciones el inventario y la conservación del patrimonio cultural de la nación. Pese a los avances, falta mucho camino por 
recorrer, pues poco vale inventariar si no se cuenta con las medidas de protección adecuadas para la conservación de los bienes culturales. Un ejemplo ilustrativo es el caso de Garagay, en el distrito de San Martín de Porres. En lo que se refiere a la función protectora, la vastedad de nuestro patrimonio hace casi imposible que el Estado cumpla eficazmente sus labores de conservación y restauración.

En cuanto al papel educativo y cultural de las instituciones que velan por la conservación del patrimonio, el Ministerio de Educación debería buscar una forma de difusión más sólida y efectiva.

Es inconcebible que las instituciones culturales vinculadas al patrimonio no promuevan el respeto y la conciencia de identidad cultural. Se debería normar, como requisito de funcionamiento, que los medios de comunicación social, públicos o privados, difundan programas culturales que enriquezcan el conocimiento de la población sobre los sitios arqueológicos y contribuyan a evitar su destrucción. Otra alternativa es la organización de exposiciones al alcance de todos los estratos sociales, e incluso programar concursos desde las escuelas, con el fin de fomentar la protección de nuestro patrimonio cultural.

Esta ley no ha contado con el apoyo necesario de los organismos competentes, y menos aun con lineamientos legales sólidos que sustenten la actividad turística. En sus casi quince años de vigencia se han aprobado decretos supremos que, en lugar de servir de apoyo, más bien se oponen a lo establecido en las normas internacionales de la Unesco. Tal es el caso del reciente D.S. 046-PCM, que modifica el reglamento de calificación de las zonas arqueológicas ocupadas por asentamientos humanos.
Ley Orgánica de Municipalidades. Título III. Capítulo II: De las Funciones Específicas ( 9 de junio de 1984)

Esta norma establece, en su artículo 67, que las municipalidades deben promover la cultura, la educación, el turismo, la recreación, los deportes, así como la conservación de monumentos. Asimismo, difundir e impulsar actividades como la creación de grupos culturales y folclóricos, y realizar espectáculos para fomentar el turismo. Pero el punto más interesante dice lo siguiente: "Las municipalidades tienen como función promover y asegurar la conservación y custodia del patrimonio cultural, colaborando con los organismos regionales y nacionales en su restauración y conservación". Tal enunciado es una falacia, ya que existen muchos ejemplos de atropello a los bienes culturales, como lo sucedido en el Asentamiento Humano 12 de agosto, en el distrito de San Martín de Porres, a cuyos pobladores se les otorgó títulos de propiedad pese a encontrarse en una zona arqueológica.

\section{Turismo}

\section{Marco conceptual}

Etimología.- El turismo es una actividad multisectorial que requiere la concurrencia de diversas áreas productivas de los sectores público $y$ privado. Carece de límites estrictos y de un producto tangible, por lo que se le considera la mejor producción de servicios.

\section{Para nuestro desarrollo partimos de la base etimológica:}

Origen hebreo antiguo.- Tur es hebreo antiguo y ya no existe en el moderno; corresponde al concepto de viaje de descubrimiento, exploración.

Origen latín .- La palabra tur tiene su origen en el sustantivo latín tornus que significa torno, y el 
verbo tornare que significa redondear, tornear. En latín vulgar, tornare quiere decir girar y su connotación resultaría sinónimo de "viaje circular".

Interpretación inglesa .- Data del siglo XII. A partir del sustantivo tornus se llega a la palabra torn, y aunque es difícil determinar qué vocablos proceden directamente del latín, lo importante es que nos da la idea de giro, de vuelta al punto de partida. Esto se deduce claramente de la raíz común torn. Recién en el siglo XVIII, en 1746, se conoce la frase "to take a turn", que significa "en o alrededor de un lugar, montando o manejando". Ya en 1760, "to take a tour" se interpreta como: "circuito de viaje en el cual muchos lugares son visitados para recreación o negocio".

Interpretación española .- Luis Fernández Fúster afirma que la primera vez que se usa la palabra tour es precisamente en la portada de un libro inglés sobre España. El texto, escrito por Henry Swinburne, se titula Picturesque tour Spain y fue publicado en 1810. En 1828 Stendhal publica sus excursiones por Francia con el título Memorias de un turista. Después tour y tourism se generalizan. En el siglo XVII se publicaron artículos referentes a tours. El Diccionario de la Real Academia Española, en su edición de 1939, incorpora las palabras "turismo" y "turista". Por turismo dice: "afición de viajar por el gusto de recorrer un país y la organización de los medios conducentes a facilitar estos viajes". Al turista lo define como: "la persona que practica el turismo".

Definiciones - La Organización Mundial del Turismo propone su definición: "Las actividades que realiza la persona durante sus viajes en lugares distintos al de su entorno habitual por un período de tiempo consecutivo inferior a un año, con fines de ocio, por negocios y otros motivos". Este concepto es el que consideramos más acorde con nuestra realidad, y nos sirve de punto de partida para nuestro análisis.

Hunzinker y Kraft, especialistas de la Universidad de Berna-Suiza, definen al turismo: "Es el conjunto de las relaciones y fenómenos producidos por el desplazamiento y permanencia de personas fuera de su lugar de domicilio, en tanto que dichos desplazamientos y permanencia no estén motivados por una actividad lucrativa".

En el nuevo marco legal peruano se distinguen dos tipos de turismo: el turismo interno, realizado en el territorio nacional por turistas domiciliados en el país; y el turismo receptivo, realizado en el territorio nacional por turistas domiciliados en el exterior. A estas definiciones se suman la de actividades turísticas, como derivadas de las interrelaciones entre los turistas, los prestadores de servicios turísticos y el Estado; y la de servicios turísticos, los cuales satisfacen las necesidades de los turistas.

\section{Aspectos generales}

Turismo como corriente de viajeros.- La tesis de Ricardo de la Cierva y Primault parte desde el punto de vista subjetivo, al considerar al turismo un hecho primordialmente humano, motivado sólo por el deseo de reposo, cambio de ambiente, y necesidades espirituales o intelectuales.

Turismo como industria.- En este aspecto encontramos la definición en la Real Academia Española: "La industria del turismo es la organización que existe en cada país para hacer el desplazamiento de quienes vienen a él y se trasladan en forma temporal y sin finalidad de lucro".

Turismo como mercado.- Aquí se retoma el concepto planteado por Hunzinker y Kraft, y se considera al turismo como mercado.

Teniendo en cuenta las definiciones anteriores, cabe destacar que, en primera instancia el turismo es considerado una industria poco explotada en nuestro medio $y$, en segundo lugar, se trata de una actividad sin fines lucrativos. 


\section{Marco normativo}

En el Perú, la legislación turística se ha incrementado debido a la importancia que ha adquirido este sector. En primer lugar, se expidieron los decretos supremos y se promulgaron los reglamentos de control a los servicios turísticos (establecimientos de hospedaje, restaurantes y agencias de viaje). Posteriormente, se aprobó la primera Ley de Turismo (24027), el 14 de febrero de 1984, hoy derogada.

El Decreto Supremo № 004-74-IT/DS, en su artículo 4, nos da, por primera vez, una definición del turista: "Extranjero residente fuera del país que ingresa al territorio nacional por un período no menor de 24 horas ni mayor de 90 días con finalidad cultural, deportiva, entretención o por razones de salud, familiares, estudios, peregrinaciones religiosas y que no podrá desarrollar actividad lucrativa o remunerada".

La actual Constitución, en su Título III, Del Régimen Económico, Capítulo II, Del Ambiente y los Recursos Naturales, no contiene artículos que promuevan el turismo, pero sí prescribe la protección al patrimonio nacional, los recursos naturales, el medio ambiente, la diversidad biológica y la Amazonía (artículos del 66 al $69)$.

El 2 de junio de 1998 se promulgó la nueva Ley de Desarrollo de la Actividad Turística (26961), que constituye el nuevo dispositivo legal para el turismo y que intenta llenar los vacios de la Ley 24027 . Esta norma es genérica y a la fecha no cuenta con un reglamento para su aplicación.

A continuación analizaremos los principales artículos de la Ley de Desarrollo de la Actividad Turística (26961). El artículo segundo del Título Preliminar establece que el Estado debe otorgar a la empresa privada las garantías suficientes para el crecimiento en los campos económico y social. Esto se encuentra ratificado en el inciso $1 \mathrm{del}$ mencionado artículo. Si nos referimos al turismo como actividad generadora de divisas, es necesario concientizar antes a la población sobre las distintas expresiones culturales que constituyen el patrimonio cultural.

La actividad turística, acorde con las nuevas tendencias económicas, debe dar lugar a la libre competencia y, a la vez, ofrecer productos de óptima calidad. Aquellos lugares que aún no han podido ingresar en el rubro turístico, deberían acogerse a este principio, por ejemplo, los restos arquitectónicos de Choquequirao en la provincia de La Concepción, Cuzco.

El artículo 3 define a los actores de la dinámica turística. En primer lugar, se establece que el turista debe estar lejos de toda actividad lucrativa, salvo el negociante debidamente autorizado por ley. El turista debe ser bien recibido y protegido por los dispositivos legales peruanos; tiene, asimismo, la libertad de decidir por el mejor paquete turístico, según la oferta y la demanda. Los prestadores de servicios turísticos -personas naturales o jurídicas- deben demostrar probidad y experiencia, así como solvencia económica para avalar las actividades que desarrollan.

El aspecto social es un punto importante. El Perú es un país receptivo pero, debido a la ola de violencia que sufrió y que afectó el Estado de Derecho, experimentó una baja en el turismo, que hizo inaplicable el aspecto normativo. Hoy ya hemos superado esta "enfermedad" $y$ apreciamos el incremento de visitantes, incluso mayor al propuesto por el actual gobierno.

El Estado debe proteger el turismo, pero lejos de toda intención paternalista. La Constitución Política establece que el Perú está regido por la economía social de mercado (artículo 58). Por consiguiente, el Estado no puede obstaculizar el desarrollo, ni ser una estructura elefantiásica que incumpla con la Constitución e impida la iniciativa turística. Si bien el país no ha consolidado el proceso de descentralización, el turismo puede alentar que el Perú deje de gravitar en la capital para, de una vez por todas, impulsar el desarrollo de las provincias.

El Título I .- El primer título de la referida 
ley señala que el Ministerio de Industria, Turismo, Integración y Negociaciones Comerciales Internacionales coordina con organismos gubernamentales y privados, y es el único que puede establecer, de acuerdo con la ley, la política de turismo. Sin embargo, el Poder Legislativo, a través de proyectos, y en especial con la dación de la ley vigente, interviene en la política turística, al punto que a veces se duplican funciones con otros organismos como el Instituto Nacional de Cultura. El Poder Ejecutivo actúa bajo los mismos lineamientos del Legislativo, pues muchas propuestas han quedado en letra muerta, por no cumplir los requisitos para ser considerados en el presupuesto nacional.

Entre las funciones del ente rector de la actividad turística, la ley establece el diálogo constante con las entidades del turismo, pues este mercado debe explotarse en conjunto para obtener mejores logros.

El Título II.- Competencias de otros Organismos, debemos mencionar que, efectivamente, en la actualidad algunos alcaldes criollos suelen promover acciones y programas; $y$ es que la riqueza de recursos y de patrimonio del Perú permite que el turismo sea una fuente de ingresos para las localidades. Vimos hace poco cómo, producto de los embates del fenómeno de "El Niño", se formó una laguna que fue aprovechada para fines turísticos.

Consideramos que, pese a las críticas, la ley vigente es buena, ya que permitirá que se presenten más iniciativas y que éstas sean atendidas rápidamente. El plazo de 30 dias que establece obliga a revisar inmediatamente dichos proyectos, con lo cual se evita su prolongado archivamiento.

El Título III.- Del Comité Consultivo de Turismo, se refiere a la creación del mismo como ente coordinador en el sector privado. De ahí que entre sus miembros estén Canatur, Promperú y otros organismos relacionados con la actividad turística. Antes de la constitución de este comité,
Canatur realizaba las coordinaciones entre los organismos del sector privado del turismo. La idea de tener un comité es una buena medida porque formaliza cualquier tipo de acción entre las instituciones de este sector.

El Título IV.- Trata sobre los Recursos Turísticos. Acorde con el tema de la globalización y la empresa moderna, la perfectible coordinación entre los organismos y las autoridades públicas dará lugar a una mejor utilización, cuidado y administración del patrimonio cultural y natural de la nación. Ello evitará desatinos tales como ciertas "audacias" urbanísticas, que lejos de mejorar e innovar, nada aportan al desarrollo cultural.

El artículo 14 regula la declaración de zonas de reserva turística. El país posee espacios que deben ser atendidos y toda iniciativa empresarial tiene que contemplar la salvaguarda del patrimonio; sin embargo, hay que saber distinguir las zonas de importancia.

Discrepamos con el artículo 15, pues resta iniciativa al Poder Legislativo. Como hemos señalado anteriormente, muchas propuestas del Congreso no han sido aceptadas, por ser de competencia del Instituto Nacional de Cultura. Por ejemplo, para el caso de la declaración de patrimonio cultural. En una democracia estas propuestas deberían partir de cualquier persona natural o jurídica- capaz de entender el problema del turismo. El ministerio puede ser el órgano competente, pero las iniciativas no tienen por qué estar circunscritas a su autoridad.

En el artículo 16 encontramos una medida acertada sobre las restricciones a la explotación excesiva de un recurso turístico. Esta situación puede ser controlada directamente mediante una comunicación del ministerio respectivo al Ejecutivo, órgano competente para declarar o imponer restricciones en el menor tiempo posible, pues, a diferencia del Congreso, no tiene que discutir sus posiciones con ningún grupo político. Esta regulación se encuentra ratificada en la Constitución (artículos 66, 67 y 68). Por tanto, coincidimos en que el Estado debe 
cuidar nuestro patrimonio cultural y natural. No se pueden explotar yacimientos, ni se puede extraer ningún valor cultural, como últimamente hemos visto en el contrabando de piezas arqueológicas, como el protector coxal del Señor de Sipán.

El Título V.- De los Prestadores de Servicios Turísticos destaca la labor de los especialistas en este campo. Las agencias de viaje y turismo han proliferado en los últimos años. La calidad no ha sido óptima, debido al desorden y la falta de regulación. Los casinos de juego deben cumplir con lo establecido en el Decreto Ley 25836, aprobado en 1992, para contribuir a la mayor captación de turistas.

La publicidad, el marketing y la comunicación intensiva, son los pilares novedosos en que se apoyan los servicios turísticos. Consideramos importante elaborar un plan turístico nacional, ya que así se captarian mayores divisas y se difundiría nuestro patrimonio. Sabemos que hubo un proyecto de cooperación técnica con el Japón, el cual se frustró por la toma de la residencia japonesa en diciembre de 1996.

Los servicios turísticos extrahoteleros, a los que se refieren los incisos c) y d) del artículo 17, descentralizan esta actividad. El Perú ha recibido más de 600 mil visitantes en 1996, y las proyecciones son auspiciosas para los próximos años. Sin embargo, el Estado debe asignar mayor presupuesto a esta actividad para lograr un desarrollo similar al de otros países de América del Sur y Centroamérica. Esto obliga a replantear la cuestión hotelera, según se establece en la Semana Económica del Grupo Apoyo -1/21/9; $n^{\text {a }} 599$. Edición especial al CADE 97.

El Título VI.- De la Facilitación Turística regula la protección al visitante. No es lícito lucrar en el cobro por la prestación de servicios turísticos. Es importante cumplir esta regla, ya que el turista fortalece los lazos de unión y confraternidad entre los países. Visitar Machu Picchu, la fortaleza de Chan Chan o el Manu debería ser sinónimo de enriquecimiento cultural y personal.
A su vez, el turista está obligado a cuidar el patrimonio cultural nacional y a respetar el reglamento de los santuarios y circuitos turísticos.

El articulo 19, en concordancia con el artículo 2, inciso 4, establece que la población nacional puede ser agente activo en el proceso dinámico del turismo y contribuir al desarrollo de su región. Al respecto, el artículo $6^{\circ}$ de la Constitución Política prescribe que el patrimonio cultural pertenece a los peruanos, y todos deben tener acceso al mismo.

Las personas de la tercera edad y las discapacitadas deben tener acceso al conocimiento del patrimonio cultural y al goce de la actividad turística, sin ningún tipo de marginación. Este artículo está ratificado en nuestra Constitución (artículo 7).

Si se pretende modernizar y promover el desarrollo de la actividad turística, es necesario que se agilicen los trámites relacionados con este sector, ya que la burocracia entorpece el progreso de cualquier acción (artículo 22 de la Ley 26961).

En materia de facilitación turística, la autoridad competente es el Ministerio de Industria, Turismo, Integración y Negociaciones Comerciales Internacionales (artículo 23). Aquí se confirma la importancia que le da a sus decisiones el nuevo marco legal del turismo. El espíritu de la ley es bueno, pero no hay que olvidar que la burocracia suele imperar precisamente en los ministerios.

Para los casos eventuales de denuncias de turistas se aplica lo regulado en los artículos 24 y 25 , que establecen los órganos competentes. En materia penal, la fiscalía provincial de turismo deberá resolver los casos ilícitos que se presenten $y$, en el campo administrativo, el Indecopi, a través de sus dependencias, previa carta de poder simple, actuará en representación del turista, según lo establecido en el artículo $51^{\circ}$ del Decreto Legislativo 716 (Ley de Protección al Consumidor). 


\section{El factor mercantil en el turismo}

Para el desarrollo de la industria del turismo hay que considerar el aspecto mercantil y el marketing. Tradicionalmente las empresas de servicios en general, y en particular las empresas turísticas, han ido a la zaga de las empresas del sector industrial en el uso de una planificación estratégica de mercado. Esto se debe, entre otras razones, a que hasta hace poco la industria turística ha estado compuesta por empresas de pequeña dimensión, que tienden a contemplar el estudio de mercado como algo escasamente útil o excesivamente caro. Por otra parte, el propio desarrollo expansivo del turismo durante las últimas décadas ha contribuido a que muchas empresas consideren innecesario dedicar recursos a la planificación estratégica. Creemos que las nuevas condiciones y las exigencias del mercado son, sin embargo, implacables y a menos que se resignen a la marginalidad, las empresas y los destinos turísticos deben incorporar a su gestión el estudio del mercado.

En estas circunstancias, la planificación de marketing, como filosofía y proceso sistemático de gestión orientado a anticipar y satisfacer las necesidades del consumidor, adquiere gran importancia.

\section{El turismo y sus efectos en el patrimonio cultural}

El turismo produce diversos efectos en las comunidades y centros receptores. La mayoría de los estudios se refieren al impacto económico y social. En cuanto al medio natural, los trabajos son aún escasos y su difusión prácticamente nula.

Los efectos del turismo en el patrimonio cultural han sido olvidados por los investigadores. Existen muy pocos trabajos y casi todos abordan el problema de manera tangencial. Sin embargo, el turismo no es el principal agente de deterioro o transformación de los atractivos culturales. También lo son, en mayor medida, el crecimiento demográfico, la urbanización mal entendida, el desarrollo acelerado de la especulación inmobiliaria, los cambios en el uso del suelo y la falta de planificación, entre otros.

El turismo se torna peligroso para el patrimonio cuando se enfoca en gran escala. Al promover este tipo de turismo el Estado busca captar más divisas. En los proyectos no se indican las medidas o programas que se desarrollan para proteger los ecosistemas turísticos. En todo momento vemos cómo se priorizan los beneficios económicos que genera el turismo, pero no las medidas concretas que salvaguardan el patrimonio cultural. En esto influyen la ausencia de planificación y la especulación de la tierra.

\section{Sugerencias para la elaboración de futuras normas y proyectos de inversión en el sector turístico}

El marco jurídico es el aliciente $y$ protector del patrimonio cultural. Frente a la ola pragmática que desconoce el caudal cultural, las leyes deben motivar el turismo, no ahuyentar la inversión privada. Los proyectos de ley sobre turismo no pueden ser trabajos oportunistas que los responsables presenten para ganarse la simpatía de los habitantes del lugar a quienes están dirigidos. Deben ser elaborados a conciencia, y proponer leyes que verdaderamente sean necesarias, sin usurpar las funciones de instancias destinadas especialmente a la promoción del turismo y del patrimonio cultural. Conforme progrese nuestra sociedad y surjan nuevas formas de mercado turístico, la legislación tendrá que estar a la par de esta inminente evolución.

El Estado debe destinar un mayor presupuesto y motivar la inversión extranjera en el sector. Según los teóricos de las finanzas, el turismo está integrado a la empresa moderna y ésta, a su vez, debe ser una unidad relacionada con el Estado, el cual, mediante una legislación 
apropiada, es el aval de la industria turística. EI turismo, por tanto, debe ser dinámico y previsor activo de un futuro cambiante.

Consideramos necesario que el Estado, al elaborar normas legales y proyectos de inversión, tome en cuenta todos los factores que influyen en la problemática del turismo. Estos son: la economía, la cultura, el factor humano, el marco económico, las instituciones culturales. Sin olvidar un aspecto que, creemos, es fundamental: la educación de la población.

\section{Conclusiones}

1. El Perú tiene un rico y envidiable patrimonio cultural, al punto que fácilmente podría triplicar el número de turistas y superar el millón.

2. Es preciso que los peruanos dejen de ignorar su patrimonio, su cultura y su tradición. El Estado, a través del Ministerio de Educación, tiene la responsabilidad de educar a la población al respecto. Para ello se debe aprovechar la cobertura de los medios de comunicación social.

3. El marco jurídico establece las bases para el desarrollo del turismo, pero debe considerar entre sus lineamientos a la investigación, conservación y uso turístico de nuestro legado histórico.

4. El actual gobierno se ha preocupado por el turismo, como lo demuestra la dación de diversos dispositivos jurídicos. Por ejemplo, el D.S. 049-98-PCM, publicado el 13 de diciembre de 1998, declara días feriados no laborables para trabajadores del sector público durante 1999, con el propósito de alentar el turismo interno y estimular el desarrollo de la industria turística.

5. Algunas propuestas legales y técnicas de la Unesco son aplicadas en el Perú desde hace buen tiempo, aun sin contar con los recursos necesarios. A fines de 1998 se realizó en el Cuzco el Primer Congreso Extraordinario de
Defensa del Patrimonio Cultural y Natural del Perú, donde se analizó el uso turístico de nuestro legado histórico.

6. Al promulgar leyes, es preciso conocer la visión del mundo sobre el patrimonio. El desarrollo de estrategias de difusión es crucial para el progreso de la actividad turística.

7. Es indispensable encaminar la inversión nacional, planificar el estudio del mercado, crear fondos de inversión que generen riqueza y no lucrar con el patrimonio cultural sin objetivo alguno, sino en su beneficio.

8. Finalmente, es importante continuar con la misma celeridad y paso firme en el mejoramiento del marco de seguridad ciudadana, e inculcar el respeto a las leyes, porque sólo así, con un país pacificado donde el Estado de Derecho no sea una falacia sino una realidad, podremos edificar una nación de verdad. El turista vendrá cuando sepa que el Perú ya dio este gran cambio.

\author{
Antonio La Cotera \\ Facultad Ciencias de la Comunicación \\ Universidad San Martín de Porres \\ Lima, Perú \\ Jlacotera@usmp.edu.pe
}




\section{BIBLIOGRAFIA}

AVALOS DE MATOS, Rosalía y RAVINES, Rogger "Las antiguedades peruanas y su protec1974 ción legal". Revista del Museo Nacional. Tomo XL. pp. 363-458.

BONAVIA, Duccio

1985 "Perú". H. Cleere (editor):

Approches to the Archaeological Heritage Cambridge. pp. 109-115.

\section{CASTILLO, Cecilia}

1990 Turismo, fundamentos y desarrollo. Edit. Art. Lautrec. p.244.

CUADROS VILLENA, Carlos

1998 Derechos Reales. Tomo I. Edit. Latina S.A. 1ra. edic. p.296.

"Bienes del patrimonio cultural de la nación. Ley 24047".

Revista Foro. Colegio de Abogados de Lima. s/f.

\section{GODOY. Luis}

1979 Antecedentes legales de protección del patrimonio monumental de la nación. Indice Cronológico. Instituto Nacional de Cultura. Centro de Investigación y Restauración de Bienes Monumentales. Departamento de Investigación del Patrimonio Monumental.

\section{GUZMAN MARQUEZ, Francisco}

1988 "La cultura y el patrimonio cultural". Primer Foro por la Defensa del Patrimonio Arqueológico, Histórico y Subacuático. Casa del Gobernador. Fuerte de San Juan de UIma.

\section{IRIARTE BRENNER, Francisco}

1990 "Patrimonio cultural e identidad". "La conservación de nuestro patrimonio cultural". Diario Oficial El Peruano. Página Opinión.
LA COTERA C., Antonio

1996 El patrimonio cultural peruano y su legislación. Tesis inédita para optar el título de abogado. Facultad de Derecho de la Universidad de San Martín de Porres.

LAMAS PUCCIO, Luis

1984 "Los delitos contra el patrimonio cultural". Revista Foro № 1. Colegio de Abogados de Lima. pp. 47-57.

LA ROSA, Iván

$\mathrm{s} / \mathrm{f} \quad$ Legislación turística,m1.

LEON, Rafael

1997 "Turismo: cómo promover el turismo en el Perú". Revista Debate. Vol. XIX. № 94‥ Mayo-junio.

MESEGUER ILLAN, Diego

1998 "Nuevas tendencias en educación turística". En Revista Nuevos Comentarios № 5. Facultad de Ciencias Sociales. Universidad Inca Garcilaso de la Vega. Pp. 36-39.

Ministerio de Industria, Turismo, Integración y Negociaciones Comerciales Internacionales: "Mercado Turístico".USMP-TURISMO. L11.02.06/B23.

MOULD DE PEASE, Mariana:

1998 "Estudiantes turistas". Revista Debate. Vol. XVIII. № 88. mayo-junio.

o "Un anuncio histórico". El Comercio. Opinión. p. A-2.

o "Algunos alcances para el turismo cultural". El Comercio. p. F-5.

OSSIO, Juan; MILLONES, Luis; MATOS, Ramiro;LLORENS, J.A.; OLIVA, Félix; VARON, Rafael;WILLIAMS,Carlos;STASTNY, Francisco 1986 Patrimonio Cultural de la Nación. Balance $y$ perspectivas. FONCIENCIAS (Asociación peruana para el Fomento de las Ciencias Sociales). 
ZUÑIGA QUIROZ, Carlos

1998 "Los retos del Comité Consultivo". El Comercio. Opinión.

\section{BIBLIOGRAFIA LEGAL}

Constitución Política del Perú de 1979.

Constitución Política del Perú de 1993.

Ley 6634 del 13 de junio de 1929.

R.S. 74 del 31 de marzo de 1933. Reglamento de la Ley 6634 .

Ley General de Amparo al Patrimonio Cultural de la Nación № 24047 del 3 de enero de 1985.

Ley 24193 del 19 de junio de 1985.

Decreto Ley 25644 del 29 de julio de 1992.

Decreto Ley 26005 del 27 de diciembre de 1992.

Ley 26576 del 16 de enero de 1996.

Ley General de Turismo № 24027 del 14 de febrero de 1984.

Decreto Supremo № 039-85-ICTI/TUR. Reglamento de la Ley General de Turismo.

Ley para el Desarrollo de la Actividad Turística № 26961, promulgada el 2 de julio de 1998.

Ley Orgánica de Municipalidades № 23853 del 28 de mayo de 1984. 